Syntax Idea: p-ISSN: 2684-6853 e-ISSN: 2684-883X

Vol. 3, No. 6, Juni 2021

\title{
STRATEGI PEMANFAATAN FACEBOOK MARKETPLACE DALAM MANAJEMEN PERIKLANAN
}

\section{Arizal, Rika Apriany Sukmana, Yusrina Ulfah, Syahrial Shaddiq, Mohammad Zainul}

Universitas Islam Kalimantan, Indonesia

Email: rizal0053@gmail.com, sukma.batola@gmail.com, yusrina_ulfah@gmail.com syahrial.shaddiq@mail.ugm.ac.id, zainul38@yahoo.co.id

\section{Abstract}

In this digital era, social media has grown into a scourge of millennial life. Social media adorns almost all platforms, both the business world, the world of information, to other lifestyles, it is like the necessities of life for the millennial community. One of the social media platforms that is busy being used by users is the Facebook marketplace application where in this application we can get both information, websites and social media. buying and selling, and communication. Buying and selling online through a marketplace platform provided by Facebook which is used to design and implement the conception, distribution of goods, ideas, and services that will be exchanged to individuals or groups to fulfill needs. So this study aims to clearly see the role of the facebook marketplace platform as a media marketplace that is much needed by the public and a marketing strategy that is usually done in the facebook marketplace social media. The research method used is descriptive literature study. This research discusses about Bintang Jaya Grafika as one of the sellers who use the platform as a promotional material. This is a creative marketing strategy to attract buyers. The use of a Facebook marketplace can be a new idea in a cheap and effective marketing strategy in increasing sales and good promotions.

Keywords: marketing strategy; social media; Facebook Marketplace

Abstrak
Dalam era digital seperti saat ini, media sosial tumbuh menjadi sebuah momok
kehidupan milenial. Media sosial menghiasi hampir di seluruh platform baik dunia
usaha, dunia informasi, hingga lifestyle lainnya, sudah seperti kebutuhan hidup
masyarakat milenial. Salah satu platform media sosial yang ramai digunakan oleh
pengguna adalah aplikasi facebook marketplace dimana dalam aplikasi tersebut kita
dapat memperoleh baik informasi, situs jual beli, dan juga komunikasi. Jual beli
secara online melalui platform marketplace yang disediakan oleh Facebook yang
digunakan untuk merancang serta melaksanakan konsepsi, distribusi barang, ide,
dan jasa yang akan dipertukarkan kepada individu maupun kelompok sebagai
pemenuhan kebutuhan. Sehingga penelitian ini bertujuan untuk melihat jelas peran
platform facebook marketplace sebagai sebuah media marketplace yang banyak
dibutuhkan oleh masyarakat dan strategi pemasaran yang bisa dilakukan dalam
media sosial facebook marketplace. Metode penelitian yang digunakan adalah studi
How to cite: Arizal, Rika Apriany Sukmana, Yusrina Ulfah, Syahrial Shaddiq, Mohammad Zainul (2021) Strategi
Pemanfaatan Facebook Marketplace Dalam Manajemen Periklanan,
(3)6.
E-ISSN: $\quad$ htps://doi.org/10.36418/syntax-idea.v3i6.1244
Published by: $\quad$ Ridwan Institute


literatur deskriptif. Penelitian ini membahas tentang Bintang Jaya Grafika sebagai salah satu penjual yang menggunakan platform sebagai bahan promosinya. Hal ini merupakan salah satu strategi pemasaran yang kreatif untuk menarik minat pembeli. Penggunaan facebook marketplace dapat menjadi ide baru dalam strategi pemasaran yang murah dan efektif dalam meningkatkan penjualan dan promosi yang baik.

Kata Kunci: strategi pemasaran; media sosial; facebook marketplace.

\section{Pendahuluan}

Keberadaan Iklan ditengah peradaban manusia dan sebelum Gutenberg menemukan sistem percetakan pada tahun 1450, Peradaban iklan sudah dikenal dalam bentuk pesan berantai. Dalam proses kegiatan jual beli dalam masyarakat, pesan berantai merupakan metode yang efektif yang kala itu mayoritas masih belum mengenal huruf, dengan cara barter. Dalam dunia pemasaran pesan berantai dapat disebut sebagai the word of mouth (Kasali, 2007).

Begitu halnya iklan ditengah peradaban modern, sebagai konsumen kita semua adalah sasaran iklan. Masyarakat sebagai konsumen dalam kehidupan yang mengisi waktu hampir setiap hari adalah media periklanan. Periklanan dapat melalui media cetak, media elektronik, bahkan melalui jagat maya yaitu media online.

Industri dan manajemen pemasaran media tidak hanya dikaitkan dengan dunia periklanan. Bahkan lebih dari itu, periklanan sangat segnifikan dengan dunia kewirausahaan, pemasaran sebuah produk, dan hubungan masyarakat (public relations). Hipotesis yang paling ideal dan logis dalam sudut pandang ini adalah bahwa tanpa sebuah bantuan iklan, tidak akan menjamin sebuah produk bisa "laris-manis" di pasaran. Dengan demikian, iklan sangat berpengaruh besar terhadap lonjakan pendapatan sekaligus citra media.

Periklanan adalah bentuk komunikasi komersil dan non personal terhadap sebuah organisasi dengan berbagai macam produknya yang ditujukan kepada khalayak melalui media yang bersifat massal seperti televisi, radio, Koran, majalah, directmail, atau kendaraan umum (Wirasari \& Ferdiana, 2018).

Persaingan dunia Persaingan dunia usaha dijagat maya tampak kian gencar seiring dengan tumbuhnya perekonomian. Dengan berbagai jalan, terutama dengan memanfaatkan media sosial sebagai media periklanan, kalangan prosedur saling memperebutkan perhatian dari calon konsumen. Kita dapat memperhatikan maraknya iklan yang bertebaran di media sosial, iklan melalui jagat maya boleh dikatakan telah menjadi bagian dari kehidupan kita sehari hari yang kehadirannya nyaris tidak pernah kita sadari (Tasruddin, 2015).

Penampilan iklan terus berevolusi dengan panduan teknologi informasi seraya menambah unsur persuasi didalamnya. Dengan berkembangnya dunia teknologi informasi dan komunikasi, seseorang sudah mampu untuk melakukan kegiatan berkomunikasi dengan baik, sehingga secara tidak langsung masyarakat disebut sebagai masyarakat informasi. Dengan berkembangnya teknologi informasi skala masal, maka 
teknologi mampu mengubah bentuk peradaban manusia, dari masyarakat dunia lokal menjadi sebuah peradaban masyarakat dunia global, sehingga berpengaruh terhadap perubahan peradaban manusia (Haryati, 2019). Dengan dukungan teknologi informasi saat ini, seseorang berkomunikasi tidak harus bertatap muka. Manusia kini memiliki alternatif media komunikasi dengan menggunakan social network atau situs jejaringan sosial.

Carlos Zerrweck yang dikutip dalam penelitian sebelumnya yang berjudul social media, advertising, and internet use among general and bariatric surgeons, mengatakan Media sosial telah menjadi alat penting dalam kehidupan kita sehari-hari. Alat internet dan media sosial meningkatkan komunikasi, pendidikan, penyampaian layanan, pemasaran dan periklanan bahkan pelayanan Kesehatan (Zerrweck et al., 2020).

Periklanan Media Sosial dapat didefinisikan sebagai "Iklan online yang menggabungkan interaksi pengguna yang telah disetujui oleh konsumen untuk ditampilkan dan dibagikan. Iklan yang dihasilkan menampilkan interaksi ini bersama dengan orang pengguna (gambar atau nama) dalam konten iklan (Ertemel \& Ammoura, 2016).

Menurut Ramadhoni, Media sosial adalah seperangkat alat komunikasi dan kolaborasi baru yang memungkinkan banyak jenis interaksi yang sebelumnya tidak tersedia untuk orang biasa. Saat ini, cara terbaik untuk mempromosikan apa pun adalah dengan menggunakan media sosial. Dengan menggunakan media sosial, masalah pengembangan iklan dapat teratasi (Romadhoni, Siallagan, \& Mayangsari, 2019).

Alat teknologi komunikasi informasi dan situs jejaring sosial adalah penting bagi kehidupan pribadi orang seperti yang telah dicerminkan oleh statistik, yang menunjukkan bahwa ada 2,82 miliar pengguna media sosial di seluruh dunia, 6,8 miliar pengguna ponsel dan tingginya penggunaan teknologi Web. (Cordero-Gutiérrez \& Lahuerta-Otero, 2020) bentuk nyata dari media baru (new media) berbasis kemajuan teknologi komunikasi yang didukung oleh teknologi informasi dan komunikasi (Information and Communication Technology) adalah media sosial yang kini marak dipergunakan oleh khalayak. Facebook, twitter dan youtube merupakan situs media sosial yang popular pada saat ini (Suryani, 2014). Dalam teknologi komunikasi berbasis media sosial, perlu dikembangkan pendekatan komunikasi yang mensyaratkan beberapa hal (Suryani, 2014) seperti terdapat berikut ini :

a. Transparant, terdokumentasi secara digital dan semua orang dapat mengaksesnya,

b. Authentic, ide yang dituangkan belum pernah ada sebelumnya dan dimana didalamnya mengandung keunikan,

c. Genuine, tidak dibuat-buat.

d. Sincere, memaknai suatu kejujuran yang terdapat dari sebuah pesan yang disebarluaskan

Dalam perkembangan komunikasi, sosial media dapat peningkatan nilai (value) dari para pelakunya, dengan prinsip membangun relasi antara perusahaan dengan fans atau follower. Daya bidik sosial media terhadap citra perusahaan maupun brand, bahkan mampu menekan biaya promosi yang biasanya harus dilakukan secara konvensional 
oleh perusahaan (Suryani, 2014). Menurut (Puspitarini \& Nuraeni, 2019) ada enam kategori besar media sosial, yaitu:

1. Social networking, salah satu sarana yang dapat digunakan untuk melakukan interaksi adalah social networking, efek yang dihasilkan dari interaksi tersebut di dunia virtual. Karakter utama yang terdapat dalam jejaring sosial yaitu penggunanya membentuk jaringan pertemanan baru. Kesamaan pada hal yang sama membuat terbentuknya jaringan pertemanan baru, seperti kesamaan hobi. Contoh dari jaringan sosial adalah instagram dan facebook.

2. Blog merupakan media sosial yang memudahkan pengguna untuk mengunggah dokumentasi aktivitas sehari-hari, memberikan komentar dan berbagi kepada pengguna lainnya, seperti berbagi tautan informasi, web dan sebagainya.

3. Microblogging adalah jenis media sosial yang memfasilitasi pengguna untuk menulis dan mengunggah kegiatan serta pendapat-nya. Secara historis, kehadiaran jenis media sosial ini merujuk pada munculnya Twitter yang hanya menyediakan ruang tertentu yaitu maksimal 140 karakter.

4. Media Sharing, sosial media ini memungkinkan pemakainya untuk menyimpan dan berbagai media seperti video, dokumen, gambar, audio secara online. Contoh dari media Jurnal Common | Nomor 1 Volume 3 | Juni 201974 sosial media ini yaitu Youtube, Flickr, Photo-bucket, atau Snapfish.

5. Social bookmarking, yaitu media sosial yang bekerja untuk menyimpan, mengelola, mengorganisasikan dan mencari suatu berita informasi informasi secara online. Situs social bookmarking yang sangat populer yaitu StumbleUpon.com, Delicious.com, Reddit.com, Digg.com, di Indonesia sendiri yaitu LintasMe.

6. Wiki adalah media konten bersama yang merupakan sebuah situs di mana kontennya merupakan hasil dari kolaborasi para pengguna. Setiap pengguna web dapat menyunting dan mengubah suatu konten yang sudah dipublikasi.

Facebook merupakan salah satu dari sekian banyaknya social network atau situs jejaringan sosial yang marak dipergunakan sebagai media komunikasi. Facebook pertama kali diluncurkan pada tahun 2006 oleh seorang mahasiswa dari Harvard University bernama Mark Zuckerberg. Pada umumnya facebook digunakan menjalin komunikasi dengan teman teman, saling mengungkapkan perasaan dan menjalin terjadinya pertemanan yang sudah ada lebih erat lagi, media hiburan dan menambah wawasan.

Fitur marketplace diluncurkan pertama kali oleh facebook di aplikasi mobile-nya pada tahun 2016. Sesuai dengan namanya, facebook marketplace merupakan sebuah pasar online untuk memfasilitasi berbagai kegiatan jual beli penggunanya. Mary $\mathrm{Ku}$ sebagai direktur manajemen produksi facebook, mengatakan bahwa marketplace dibuat karena banyaknya aktivitas jual beli dalam jejaring sosial tersebut. Sebelum diluncurkannya marketplace tercatat lebih dari 450 juta orang perbulan telah melakukan aktivitas jual beli di aplikasi facebook. Riyanto mengatakan, pengguna facebook pada tahun 2020 di Indonesia berjumlah 130 juta jiwa dengan persentase jenis kelamin pria 
44,5\% serta wanita 55,6\% dari seluruh jumlah pengguna (Simatupang, Efendi, \& Putri, 2021).

Para pelaku usaha dan jasa mulai menggunakan media Facebook pada fitur marketplace sebagai media komunikasi pemasaran dan media periklanan untuk mempromosikan produk atau jasa perusahaannya. Menurut Basu Swastha, komunikasi pemasaran adalah kegiatan komunikasi yang dilakukan oleh pembeli dan penjual dan merupakan kegiatan yang membantu dalam mengambil keputusan dibidang pemasaran untuk tujuan yang lebih baik (Haryati, 2019).

Agar produk dan jasa yang ditawarkan mampu bersaing ditengah persaingan usaha saat ini. Manajemen pihak pelaku usaha harus mampu membuat "strategi kreatif" sebagai pedoman untuk membuat iklan. Iklan-iklan yang tampil dengan berbagai atribut memang mampu menarik perhatian khalayak konsumen. Bagaimana proses dan teknik pembuatannya, iklan-iklan tersebut tidak mungkin dapat dibuat begitu saja dengan spontan. Tentu perlu adanya "pekerjaan kreatif" dalam membuat iklan agar mampu menarik perhatian konsumen, diantaranya "Strategi Kreatif pemanfaatkan facebook marketplace dalam manajemen periklanan”.

Tujuan penelitian ini untuk melihat peran platform facebook marketplace sebagai sebuah media marketplace yang banyak dibutuhkan oleh masyarakat dan strategi pemasaran yang biasa dilakukan dalam media sosial facebook marketplace. Manfaat penelitian ini untuk memunculkan ide promosi baru dari produsen atau penjual kepada pembeli menggunakan keunggulan fitur facebook marketplace dalam proses pemasaran

\section{Metode Penelitian}

Metode penelitian yang dipakai oleh peneliti adalah metode studi literatur yang dalam pemahamannya sama dengan namanya yaitu mempelajari dan mengkaji hasilhasil literature yang ada mulai dari buku, jurnal dan seluruh literature yang relevan dan mampu menunjang pembahasan dari rumusan masalah yang dipertanyakan oleh peneliti, sehingga ketika studi literature dilakukan maka metode selanjutnya yang digunakan adalah metode penelitian deskriptif melalui metode ini peneliti mulai menjelaskan pokok masalah serta jawaban yang paling menunjang untuk nantinya menguraikan sebagai bentuk pemahaman, dengan menghubungkan baik relevansi permasalahan dan jawaban yang akan dianalisis dari hasil metode studi literature yaitu penggunaan penelitian secara pustaka.

\section{Hasil dan Pembahasan}

Bintang Jaya Grafika adalah salah satu home industri percetakan yang melayani jasa percetakan. Bintang Jaya Grafika menggunakan media sosial facebook marketplace sebagai media pemasaran sebagai upaya memaksimalkan media online khususnya jejaringan sosial dalam memasarkan produk dan jasanya.

Strategi pemasaran ini menggunakan rencana dan konten yang menarik dan kreatif sehingga mampu menarik minat masyarakat dan mendorong mereka untuk menjadi pelanggan yang menggunakan jasa mereka dalam percetakan. Strategi 
pemasaran merupakan langkah-langkah yang berkesinambungan yang diupayakan oleh sebuah perusahaan guna mencapai target pemasaran terbaik dalam rangka mewujudkan kepuasan konsumen (Tasruddin, 2015). Konten marketing yang digunakan dalam memasarkan produk pada prinsipnya bertujuan untuk:

1. Mengarahkan audiens baru untuk mengidentifikasi bisnis barang atau jasa perusahaan yang beriklan.

2. Menarik audiens untuk membeli barang atau menggunakan jasa yang dipromosikan tersebut agar menjadi konsumen.

\section{A. Strategi kreatif dalam periklanan}

Istilah strategi kreatif dalam periklanan ini mempunyai arti tergantung siapa yang melihatnya. Seorang pengiklan biasanya akan berpendapat bahwa strategi kreatif adalah bentuk orientasi pemasaran yang diberikan kepada orang-orang kreatif sebagai pedoman dalam membuat suatu iklan. Setelah strategi kreatif ditetapkan, maka proses penggarapan iklan pun bisa dimulai. Strategi kreatif periklanan mencakup pelaksanaan dan pengembangan ide atau konsep yang mampu menerapkan strategi dasar dalam bentuk komunikasi yang efektif (Kasali, 2007).

Dalam kegiatan pemasaran produk dan jasanya, Ryan Jayusman sebagai owner Bintang Jaya Grafika menerapkan "strategi kreatif” dalam manajemen periklanan produknya. Dalam hal ini Ryan Jayusman pemilik "Bintang Jaya Grafika" sebagai sumber informasi langsung menerangkan bahwa memilih facebook marketplace sebagai media iklan produknya karena dianggap lebih menguntungkan, ekonomis dan efisien. Ryan membuat "konsep kreatif” dalam merancang bentuk informasi yang disampaikan dalam iklan produknya dan membuat tim kecil dalam mengelola periklanan tersebut dan menciptakan komunikasi pemasaran yang baik untuk membangun kepercayaan konsumen. Langkah pertama tim mulai membuat akun facebook marketplace dengan profil pelapak bernama "Bintang Jaya Grafika". Sebelumnya Bintang jaya Grafika menggunakan media brosur dalam periklanan. Dan mengingat konsumen di era saat ini banyak menggunakan media sosial sebagai media komunikasi, maka dari ini Bintang Jaya Grafika mulai beralih ke media pemasaran "brosur" menuju "media sosial facebook marketplace".

Strategi kreatif menurut Rangkuti, tidak hanya dengan cara membuat ide yang sesuai dengan positioning produk, tetapi juga menempatkan media yang tepat sehingga mampu menarik perhatian dan melibatkan target market serta memotivasi prospek agar mecoba produk atau jasa yang ditawarkan (Nisa, 2015).

\section{B. Perumusan Strategi Kreatif}

Menurut Gilson dan Berkman, yang mana di kutip oleh Rhenald Kasali bahwa proses perumusan strategi kreatif terdiri dari tiga tahap yang mana di lihat dari strategi kreatif sebuah iklan, yaitu (Likha Sari Anggreni et al., 2021):

1. Tahap Pertama, mempersiapkan dan mengumpulkan segala informasi pemasaran yang tepat agar orang orang kreatif dengan segera menciptakan strategi kreatif mereka. 
2. Tahap Kedua, untuk menetapkan suatu posisi dan menentukan tujuan sebuah iklan yang dihasilkan, orang orang kreatif harus masuk kedalam informasiinformasi yang telah di dapat. Pada tahap ini, ide ide yang merupakan bagian penting dari seluruh proses perumusan strategi kreatif, dihasilkan dan dikembangkan secara optimal. Untuk memperoleh itu diperlukannya diskusi yang dalam diantara orang orang kreatif.

3. Tahap Ketiga, Melakukan pemaparan hasil dari proses kreatif tersebut kepada klien agar mendapatkan persetujuan hingga akhirnya siap di eksekusi.

Dalam perumusan strategi kreatif, tahap pertama tim promosi dan iklan Bintang jaya Grafika mulai melakukan survei kecil dengan melihat apakah dan bagaimana strategi periklanan dan pemasaran jasa percetakan pelaku usaha lainnya, misalnya dengan mengecek beranda pada facebook marketplace. Selanjutnya mengumpulkan bahan-bahan atau data terkait tentang produk atau jasa yang ditawarkan nantinya, misalnya dengan mulai mengambil gambar/foto produk dari sudut yang menarik yang dilakukan oleh fotografer dari tim pemasaran. Setelah bahan sudah mulai dikumpulkan, tim mulai menentukan dimedia mana saja iklan pemasaran tersebut dimunculkan, sampai akhirnya tim sepakat memilih facebook marketplace dalam memunculkan iklannya karena dianggap lebih murah, efektif dan efesien. Langkah selanjutnya tim pemasaran Bintang Jaya Grafika melakukan diskusi kecil tentang konsep atau rancangan iklan yang ditelah dibuat agar mendapat persetujuan oleh Ryan jayusman sebagai Owner. Bintang jaya juga melakukan perbandingan dengan pelaku usaha percetakan lainnya, diantaranya survey harga, konsep desaint periklanan lainnya, serta melihat kelebihan dan kekurangan metode iklan yang ditawarkan pelaku usaha percetakan lainnya, sehingga dapat menjadi penyeimbang dalam membuat iklan Bintang jaya Grafika.

Dalam pembuatan iklan, untuk menghasilkan iklan yang baik, selain penting juga menggunakan elemen elemen dalam sebuah rumus yang dikenal dengan model AIDCA (Wiradharma \& Tanwir, 2016) yang terdiri dari :

1. Attention, pesan iklan yang kreatif harus mampu menarik perhatian audien ,ditinjau dari jenis huruf, tata letak, warna, ukuran.

2. Interest, setelah berhasil merebut perhatian audien sasaran berikutnya bagaimana agar audiens berminat dan ingin tahu lebih jauh tentang merek produk tersebut.

3. Desire, informasi yang disampaikan pada iklan harus dapat menggerakkan keinginan audien untuk memiliki atau memakai produk atau jasa yang ada diiklan tersebut.

4. Convicton, sasaran berikutnya pesan iklan harus berhasil menciptakan keyakinan audiens atas merek yang diiklankan.

5. Action, iklan berhasil mendorong audiens untuk melakukan tindakan pembelian pada produk atau jasa yang diiklankan 
Untuk menarik perhatian konsumen, Bintang Jaya Grafika bersama tim mendesaint foto sampul profil akun facebook "Bintang Jaya Grafika" diantaranya penggunaan warna full color, memperhatikan tata letak (lay out), serta memilih jenis huruf yang ditampilkan untuk memadukan antara gambar dan warna sehingga menunjukkan kekontrasan dengan akun akun lainnya. desaint sampul profil juga menggunakan slogan yang mudah diingat untuk dijadikan heatline, diantaranya “ CETAK DISINI AJA!’. Sampul profil dapat dilihat pada gambar berikut:

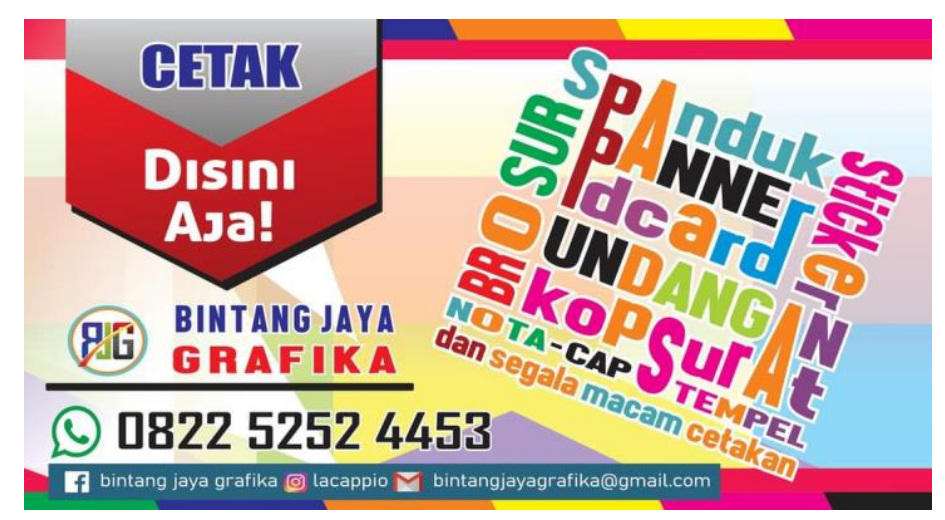

Gambar 1

Sampul Profil akun "Bintang Jaya Grafika"

Agar menambah minat dan perhatian calon penerima jasa, tim menggunakan kata-kata atau kalimat pembuka untuk dapat merangsang konsumen untuk tahu lebih lanjut tentang produk dan jasa yang ditawarkan oleh "Bintang Jaya Grafika" diantaranya menggunakan beberapa kalimat diantaranya:

“STIKER LABEL TERMURAH

Kualitas Terbaik”

“YANG MASIH BINGUNG MAU BIKIN NOTA

BERWARNA DIMANA

YANG MASIH BINGUNG DESAIN NOTANYA

GIMANA

SILAHKAN DISINI TEMPATNYA"

“CAP STEMPEL OTOMATIS TANPA BANTALAN

Murah-Cepat-Gratis Ongkir

ORDER-DESAIN-APROVE-ANTAR 
Upaya membangkitkan kebutuhan dan keinginan calon pembeli agar tidak goyah dan menumbuhkan rasa percaya konsumen terhadap produk dan jasa yang ditawarkan, Bintang Jaya Grafika melakukan beberapa kegiatan diantaranya membagikan beberapa sample produknya secara gratis kepada calon konsumennya sekaligus uji coba kualitas produk atau jasa yang dihasilkan. Misalnya dalam wawancara owner menyebutkan pernah memberikan sample produk kepada beberapa instansi pemerintahan diantaranya "Memberikan contoh produk piala dan plakat, hasil percetakan kalender, contoh brosur dan buku panduan dan contoh kartu ID card secara gratis kepada Institusi Pendidikan Poltekkes Kesehatan Kemenkes Palangkaraya". Tim juga menuliskan deskripsi keunggulan kualitas produk yang ditawarkan pada akun facebooknya.misalnya :

\section{"Deskripsi :}

1. Bahan Kualitas baik

2. Ukuran A3+

3. Kiss Cut

4. Tintah Anti Luntur

5. Print Laser mesin Konika Minolta”

"KENAPA PILIH KITA

- DESAIN BY REQUEST

- HARGA BERANI DI ADU

- PENGERJAAN CEPAT

- HARGA MURAH POOLL

- KERTAS BERKUALITAS

- BISA PAKAI NOMOR URUT DAN LOGO WARNA"

Pada tahap selanjutnya Bintang Jaya tidak lupa mencantumkan nomor kontak dan email sebagai bentuk komunikasi pemasaran. Proses pertukaan informasi dan pesan pesan mengenai produk atau jasa yang ditawarkan oleh Bintang jaya Grafika kepada konsumen dikomunikasikan melalui email dan kontak person yang tertera pada iklan dan owner dalam wawancara juga menyampaikan bahwa "iklan yang dibuat harus sesuai dengan ekspektasi apabila ingin menjaga kepercayaan konsumen, konsisten dalam beriklan dan bersikap ramah dalam menjawab pertanyaan konsumen, karena tipe konsumen ada yang hanya bertanya dan ada juga yang berminat menggunakan jasa percetakannya"

Pertukaran informasi merupakan sebuah proses komunikasi antara pengirim pesan (sender) dengan penerima pesan (receiver). Informasi diperoleh baik dari produsen ke konsumen mengenai produk yang ditawarkan maupun dari konsumen kepada produsen mengenai produk yang diinginkan (Haryati, 2019).

Interaksi sosial dapat dengan mudah dilakukan dengan desaint media online, bersifat interaktif dan berbasis teknologi internet dengan mengubah pola penyebaran informasi. Promosi dan konten yang menarik dapat mengundang perhatian pengunjung 
untuk melihat produk dan jasa yang dipasarkan (Haryati, 2019). Owner kembali menyampaikan bahwa "Dengan menggunakan media online sebagai media iklan dan pemasaran sangat berpengaruh besar terhadap peningkatan omset Bintang Jaya Grafika yang sebelumnya hanya menggunakan media lainnya dalam membuat iklan dan promosi".

\section{Kesimpulan}

Kemudahan akses internet mengantarkan masyarakat kepada dunia yang berbasis virtual, seperti halnya belanja online yang kini sudah tak asing lagi didengar ditelinga masyarakat. Ada banyak media sosial yang hadir dengan menawarkan fitur marketplace pada aplikasi mereka diantaranya facebook yang sangat disukai oleh masyarakat. Facebook mempunyai kegunaan yang signifikan dalam memasarkan produknya karena merupakan sebuah sosial media yang lebih sering diakses yang menyajikan fungsi informasi dari pengguna yang dapat membantu fokus segmentasi pasar yang tepat. Komunikasi yang terjalin di facebook sangat mudah sehingga tidak ada batasan dalam bersosialisasi sehingga terdapat komunikasi yang baik/feedback dari penjual ke pembeli atau sebaliknya. Penggunaan facebook marketplace dapat menjadi ide baru dalam strategi pemasaran yang murah dan efektif dalam meningkatkan penjualan dan promosi yang baik. 
Arizal, Rika Apriany Sukmana, Yusrina Ulfah, Syahrial Shaddiq, Mohammad Zainul

\section{BIBLIOGRAFI}

Cordero-Gutiérrez, Rebeca, \& Lahuerta-Otero, Eva. (2020). Social media advertising efficiency on higher education programs. Spanish Journal of MarketingESIC.Google Scholar

Ertemel, Adnan Veysel, \& Ammoura, Ahmad. (2016). The role of social media advertising in consumer buying behavior. International Journal of Commerce and Finance, 2(1), 81-89. Google Scholar

Haryati, Haryati. (2019). Strategi Komunikasi Pemasaran Bisnis Online Dengan Mengunakan Facebook Sebagai Media Online. Khazanah Ilmu Berazam, 2(3 Sept), 309-314. Google Scholar

Kasali, Rhenald. (2007). Manajemen Public Relations: Konsep dan Aplikasinya di Indonesia, Pustaka Utama Grafiti. Kotler, Philip., Dan Kevin Lane Keller. Google Scholar

Likha Sari Anggreni et al. (2021). Strategi Kreatif Kerajinan Payung Muto Menjadikan Desa Tanjung sebagai Desa Wisata di Klaten - Jawa Tengah. Journal of Servite, 2(1). Google Scholar

Nisa, Naima Khoiru. (2015). Strategi Kreatif Iklan Layanan Masyarakat (ILM) dalam Pemasaran Sosial. Interaksi: Jurnal Ilmu Komunikasi, 4(2), 158-164. Google Scholar

Puspitarini, Dinda Sekar, \& Nuraeni, Reni. (2019). Pemanfaatan Media Sosial Sebagai Media Promosi. Jurnal Common, 3(1), 71-80. Google Scholar

Romadhoni, Riefky Amarullah, Siallagan, Manahan, \& Mayangsari, Lidia. (2019). Virality in Social Media Advertising: A Case Study in Bandung Tourism. The Asian Journal of Technology Management, 12(3), 204-211.Google Scholar

Simatupang, Sudung, Efendi, Efendi, \& Putri, Debi Eka. (2021). Facebook Marketplace Serta Pengaruhnya Terhadap Minat Beli. Jurnal Ekbis, 22(1), 28-41. Google Scholar

Suryani, Ita. (2014). Pemanfaatan Media Sosial sebagai Media Pemasaran Produk dan Potensi Indonesia dalam Upaya Mendukung ASEAN Community 2015.(Studi Social Media Marketing Pada Twitter Kemenparekraf RI dan Facebook Disparbud Provinsi Jawa Barat). Jurnal Komunikasi, 8(2), 123-138. Google Scholar

Tasruddin, Ramsiah. (2015). Strategi Promosi Periklanan yang Efektif. Jurnal AlKhitabah, 2(1). Google Scholar

Wiradharma, Gunawan, \& Tanwir, Muhammad. (2016). Pelestarian Lingkungan Melalui Periklanan Kreatif: Sebuah Pendekatan Ekologi. Google Scholar 
Wirasari, Ira, \& Ferdiana, Tresna. (2018). Strategi Kreatif Tema Pahlawan Dalam Iklan Media Sosial Bukalapak. Atrat: Jurnal Seni Rupa, 6(2). Google Scholar

Zerrweck, Carlos, Arana, Sebastián, Calleja, Carmen, Rodríguez, Nelson, Moreno, Eduardo, Pantoja, Juan P., \& Donatini, Gianluca. (2020). Social media, advertising, and internet use among general and bariatric surgeons. Surgical Endoscopy, 34(4), 1634-1640. Google Scholar

\section{Copyright holder :}

Arizal, Rika Apriany Sukmana, Yusrina Ulfah, Syahrial Shaddiq, Mohammad Zainul (2021)

First publication right :

Jurnal Syntax Idea

This article is licensed under:

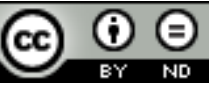

